\title{
Impact of unbalanced harmonic loads towards winding temperature rise using FEM modeling
}

\author{
Z.I.M.Yassin ${ }^{1}$, D.M.Said ${ }^{2}$, N.Ahmad ${ }^{3}$, NN Nik Abd Malik ${ }^{4}$, H.Abdullah ${ }^{5}$ \\ 1,2,3,4,5 Centre of Electrical Energy System, Universiti Teknologi Malaysia
}

\begin{tabular}{|c|c|}
\hline Article Info & ABSTRACT \\
\hline Article historys: & \multirow{11}{*}{$\begin{array}{l}\text { This paper investigates the hot spot temperature of transformer thermal model } \\
\text { due to unbalanced harmonic loads from the network. The finite element } \\
\text { method has been used to solve the coupling multiphysic for heat transfer in } \\
\text { solid and fluid. All material properties in the model were been took into } \\
\text { consideration such as copper as the coil material, iron as the core material and } \\
\text { transformer oil as the coolant material for the transformer. The transient study } \\
\text { on the model has been set for 1minutes using } 30 \text { degree celcius as the ambient } \\
\text { temperature reference. The simulation hot spot temperature result has been } \\
\text { compared for rated load (without harmonic) versus the unbalanced load (with } \\
\text { harmonic) which shown in } 2 \mathrm{D} \text { regime. It can be clearly seen the significant } \\
\text { increment of the hotspot temperature of the transformer from the rated load to } \\
\text { the unbalanced harmonic load. The result has successfully shows the detection } \\
\text { of the prospect failure of the transformer due to the harmonic current load in a } \\
\text { form of winding loss that contributes to the hotspot temperature of the } \\
\text { transformer. }\end{array}$} \\
\hline Received Jan 7, 2020 & \\
\hline Revised June 28, 2020 & \\
\hline Accepted June 30, 2020 & \\
\hline Keywords: & \\
\hline Harmonics & \\
\hline Unbalanced load & \\
\hline Unbaranced load & \\
\hline & \\
\hline Transformer & \\
\hline Finite Element Method & \\
\hline
\end{tabular}

Copyright $(0) 2020$ Institute of Advanced Engineering and Science. All rights reserved.

\section{Corresponding Author:}

Dr. Dalila Binti Mat Said,

Centre of Electrical Energy System,

School of Electrical Engineering,

Faculty of Engineering,

Universiti Teknologi Malaysia,

81310, Skudai, Johor.

Email: dalila@utm.my

\section{INTRODUCTION}

As stated in international IEEE standard, harmonics are defined as currents or voltage with frequencies that are integer multiples of fundamental power frequency. The distortion in current and voltage wave shape which was created by the drawn current nonlinear loads in high amplitude short pulses, measured in term of total harmonics distortion (THD) [1]. The generated harmonics causes additional heating in transformer components by then induce the higher losses and degradation to transformer insulation which decreases the useful life of transformer and premature failure of transformer. The additional heating is one the root cause of eddy current induction and increasing in eddy current losses causes rise in temperature of transformer which results in premature failure of transformer. Other than that, harmonics it is also said as a causes in derating transformers capacity and may need to be derated to as much as $50 \%$ capacity when feeding loads with highly distorted current waveform [2] and [3].

In sequence from the risen eddy current losses, the transformer winding insulation deterioration is strongly affected which the insulation material will be deterioted and thus reduce the effective service life of transformer [4] and [5]. Thus, it is crucial to study the hot-spot localization in transformer in order to prevent massive loss either in aspect of cost or system production. However, it is a challenge to predict the hottest spot in the transformer. In recent research publications, a lot of methods have been applied to calculate the maximum temperature rise in transformers [6], [7], and [8]. In recent years the use of embedded temperature sensors which directly measure the maximum temperature in windings insulation has been in trend. As the evolving of optical fiber technology, fiber temperature sensors then have been developed and implemented in measuring 
temperature in transformers [9], [10], [11], [12], and [13]. Although able to measure accurately the winding temperatures on-line, this approach is not practical to apply to existing in-service transformers. Other than that, the sensors has high possibility for it to have technical problem or broken and hence cannot give a clear indication of the transformer condition. There are many real site cases where the transformer is tripped due to the sensors failed to give an early warning sign of the transformer malfunction condition. Furthermore, it is difficult to justify the additional costs, particularly in applications on low-cost medium-voltage distribution transformers.

Another method to determine the temperature in transformer winding is detailed in the IEC 60076-2 Standard [14]. In order to provide a convenient method to determine the temperatures, several assumptions have been made. The calculation is achieved by determining the top-oil, bottom-oil and the average winding temperatures. The top-oil and bottom-oil temperature can be determined by immersing temperature sensors in the insulating liquid [15]. The average winding temperature is determined by measuring the total windings resistance (after disconnecting the transformer). This method is simple, quick and it is independent from the structure of transformers; hence, it could be applied for a wide range of transformer ratings. However, it is not practical for on-line monitoring implementation. Also, the additional temperature rise due to harmonic contamination was not taken into account. In the situation of harmonic, IEEE recommendation [16] suggested a correction. In this standard, the temperature rise in transformers under current harmonic condition was achieved by determining transformer losses followed by harmonic loss factors. In both standards, the hottestspot temperature was calculated but the location of the hottest-spot was not revealed. Another approach to investigate the thermal stress on winding insulation in transformers is to utilize computer-based simulation software. The Finite Element Method (FEM) is an effective computational technique that has been developed to solve a wide range of engineering problems (structural, thermal, electromagnetic, etc). FEM has been utilised in investigation of temperature rise in transformers [17], [18], [19], [20], and [21]. In relevancy to its advantages, there were numerous papers that has published many physical models of electrical equipment such as the transformer. The FEM has been applied to the transformer model in order to prove its ability to solve any engineering problems with the most acccurate results [22], [23], [24] and [25]. In these papers, the structure of transformer was simplified in the simulation to reduce its complexity and the theory of conduction heat transfer in solid (i.e. winding conductor, core and insulation) was applied to solve the thermal problem.

\section{RESEARCH METHOD}

In this study, the method has been divided into modeling of the transformer cross section and also data collection from the actual site which to be applied on the modeling. The FEM COMSOL software is used for the modeling purpose to simulate the thermal model under finite element environment.

\subsection{The thermal model for the transformer}

The figure below is illustrated the cross section of the oil type distribution transformer for three phase $2000 \mathrm{kVA}$ rating size. By assumption that the design of the three phase transformer were physically similar, the transformer model in study has been potrayed in a single phase manner. Hence, it can solve the time constraint in the geometry assembly to get the result.

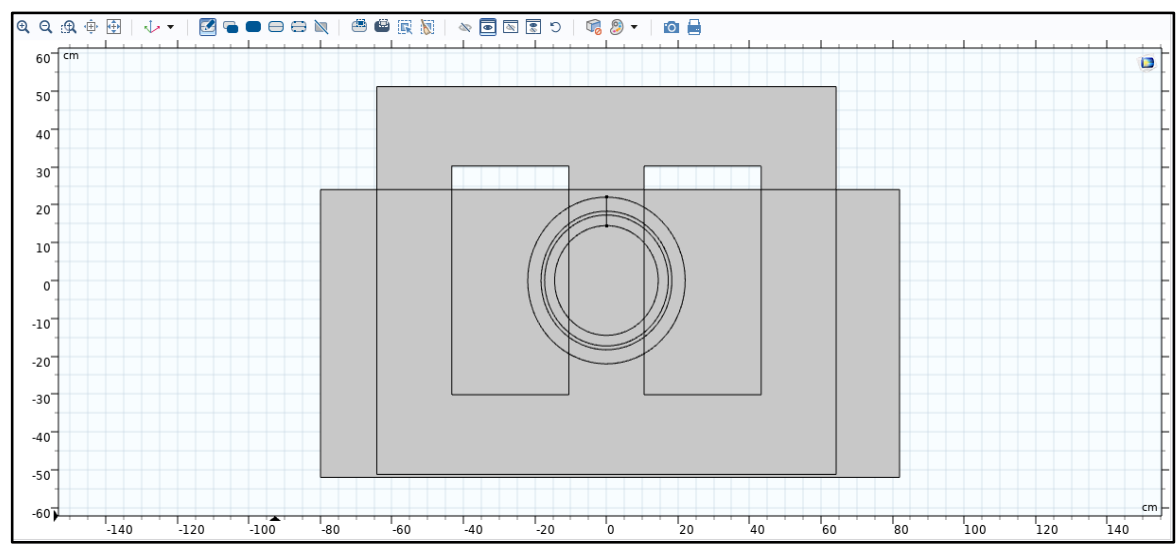

Figure 1.2D cross section geometry of transformer thermal model 
The cross section of 2D transformer geometry as in above figure had been modeled using Finite Element Method software which is known as COMSOL. The heat transfer of solid and liquid multiphysics interface was by then been applied on the transformer model. This coupling mutiphysics was dedicated to study the temperature rise of the transformer due to the losses which then contributed to the hotspot temperature of the transformer. The results were achieved by solving the governing equation for heat transfer in solid and liquid as shown below in the equation (1) and (2) respectively below [5, 16]:

$$
\begin{aligned}
& d_{z} \rho C_{p} \frac{\partial T}{\partial t}+d_{z} \rho C_{p} u . \nabla T+\nabla \cdot q=d_{z} Q+q_{0} \ldots . \\
& q=-d_{z} k \nabla T \ldots
\end{aligned}
$$

Where $d z$ is the thickness of the geometry, T is the temperature, $\rho$ is the density, $C p$ is the specific heat capacity at constant pressure, $k$ is the thermal conductivity, $Q$ is the losses which act as a heat source in this study, $q_{0}$ is the convection heat flux and $\mathrm{u}$ is the velocity of the liquid.

\subsection{The material properties of the transformer model}

As for this study, there were three set of material types that had been applied on the transformer model which including copper for the transformer winding domain, iron for the transformer core domain and transformer oil for the coolant medium. Each of the material types has their own material properties as depicted in the Table 1-3.

\begin{tabular}{|c|c|c|c|c|c|}
\hline " & Property & Variable & Value & Unit & Property group \\
\hline$\nabla$ & Heat capacity at constant pressure & $C_{p}$ & $385\left[\mathrm{~J} /\left(\mathrm{kg}^{\star} \mathrm{K}\right)\right]$ & $\mathrm{J} /(\mathrm{kg} \cdot \mathrm{K})$ & Basic \\
\hline$\nabla$ & Density & rho & $8940\left[\mathrm{~kg} / \mathrm{m}^{\wedge} 3\right]$ & $\mathrm{kg} / \mathrm{m}^{3}$ & Basic \\
\hline \multirow[t]{10}{*}{$\nabla$} & Thermal conductivity & k_iso; kii... & $400\left[\mathrm{~W} /\left(\mathrm{m}^{\star} \mathrm{K}\right)\right]$ & $\mathrm{W} /(\mathrm{m} \cdot \mathrm{K})$ & Basic \\
\hline & Relative permeability & mur_iso ;... & 1 & 1 & Basic \\
\hline & Electrical conductivity & sigma_iso... & $5.998 \mathrm{e} 7[\mathrm{~S} / \mathrm{m}]$ & $\mathrm{S} / \mathrm{m}$ & Basic \\
\hline & Relative permittivity & epsilonr_i... & 1 & 1 & Basic \\
\hline & Surface emissivity & epsilon_rad & 0.5 & 1 & Basic \\
\hline & Dynamic viscosity & $\mathrm{mu}$ & 10 & Pa.s & Basic \\
\hline & Young's modulus & $\mathrm{E}$ & $126 \mathrm{e} 9[\mathrm{~Pa}]$ & $\mathrm{Pa}$ & Young's modulus and Poisson's ratio \\
\hline & Poisson's ratio & nu & 0.34 & 1 & Young's modulus and Poisson's ratio \\
\hline & Reference resistivity & rhoo & $1.667 \mathrm{e}-8[\mathrm{oh} . .$. & $\Omega \cdot m$ & Linearized resistivity \\
\hline & Resistivity temperature coefficient & alpha & $3.862 \mathrm{e}-3[1 / K]$ & $1 / K$ & Linearized resistivity \\
\hline
\end{tabular}

Table 1. Material properties for copper

\begin{tabular}{|c|c|c|c|c|c|}
\hline$"$ & Property & Variable & Value & Unit & Property group \\
\hline$\nabla$ & Heat capacity at constant pressure & $C p$ & $440\left[\mathrm{~J} /\left(\mathrm{kg}^{\star} \mathrm{K}\right)\right]$ & $\mathrm{J} /(\mathrm{kg} \cdot \mathrm{K})$ & Basic \\
\hline$\nabla$ & Density & rho & $7870\left[\mathrm{~kg} / \mathrm{m}^{\wedge} 3\right]$ & $\mathrm{kg} / \mathrm{m}^{3}$ & Basic \\
\hline \multirow[t]{8}{*}{$\nabla$} & Thermal conductivity & k_iso ; kii =... & $76.2\left[W /\left(m^{\star} K\right)\right]$ & $W /(m \cdot k)$ & Basic \\
\hline & Relative permeability & mur_iso; m... & 4000 & 1 & Basic \\
\hline & Electrical conductivity & sigma_iso ;... & $1.12 \mathrm{e} 7[\mathrm{~S} / \mathrm{m}]$ & $\mathrm{S} / \mathrm{m}$ & Basic \\
\hline & Coefficient of thermal expansion & alpha_iso ;... & $12.2 \mathrm{e}-6[1 / K]$ & $1 / K$ & Basic \\
\hline & Relative permittivity & epsilonr_iso... & 1 & 1 & Basic \\
\hline & Dynamic viscosity & $\mathrm{mu}$ & 10 & $\mathrm{~Pa} \cdot \mathrm{s}$ & Basic \\
\hline & Young's modulus & $\mathrm{E}$ & $200 \mathrm{e} 9[\mathrm{~Pa}]$ & $\mathrm{Pa}$ & Young's modulus and Poisson's ratio \\
\hline & Poisson's ratio & nu & 0.29 & 1 & Young's modulus and Poisson's ratio \\
\hline
\end{tabular}

Table 2. Material properties for iron

Table 3. Material properties for transformer oil

\begin{tabular}{|l|l|l|l|l|l|}
\hline$"$ & Variable & Value & Unit & Property group \\
\hline$\square$ & Heat capacity at constant pressure & $\mathrm{Cp}$ & $\mathrm{Cp}(\mathrm{T})$ & $\mathrm{J} /(\mathrm{kg} \cdot \mathrm{K})$ & Basic \\
\hline$\square$ & Density & rho & rho(T) & $\mathrm{kg} / \mathrm{m}^{3}$ & Basic \\
\hline$\square$ & Thermal conductivity & $\mathrm{k}$ iso $; \mathrm{kii}=\ldots$ & $\mathrm{k}(\mathrm{T})$ & $\mathrm{W} /(\mathrm{m} \cdot \mathrm{K})$ & Basic \\
\hline$\square$ & Ratio of specific heats & gamma & 0.5 & 1 & Basic \\
\hline & Dynamic viscosity & mu & eta(T) & Pa.5 & Basic \\
\hline
\end{tabular}




\subsection{Transformer thermal model hotspot external parameters}

In this paper, the analogy of the simulation result was divided into two conditions which were simulation with the rated load for the transformer and another one was simulation with unbalanced load with harmonic current content. The total power losses from both condition were treated as the heat source in the governing equation in (1) and the simulation result of hotspot temperature from both condition was then being compared and analysed. The rated load and the unbalanced harmonic data were taken from the field measurement using power quality analyzer as depicted in the Table 4 below. Noted that the harmonic current content data that had been used for this paper were taken from the odd harmonic order started from $3^{\text {rd }}$ until 15 th which has been assembled for 24 hours period on normal working day hours.

Table 4. Parameter of the transformer

Trasformer rating

Rated current

Reference temperature

$2000 \mathrm{kVA} 3 \varnothing 22 \mathrm{kV} / 433 \mathrm{~V}$

Primary: 52.49 A

Secondary: 2666.74 A

Ambient: $30^{\circ} \mathrm{C}$

Top oil rise: $55^{\circ} \mathrm{C}$

Average winding rise: $55^{\circ} \mathrm{C}$

Hottest-spot rise: $65^{\circ} \mathrm{C}$

\subsection{The hotspot temperature evaluation point}

As in this paper, the hotspot temperature has been investigated on selected point of the cross section of the transformer model. In figure 3, the red dot which represented the coordinate point of $(20,0)$ was selected to be evaluated for this hotspot temperature study. The significant purpose of this point selection is to see the transition of the temperature of the winding which has been immersed in the oil liquid that act as the coolant for the winding.

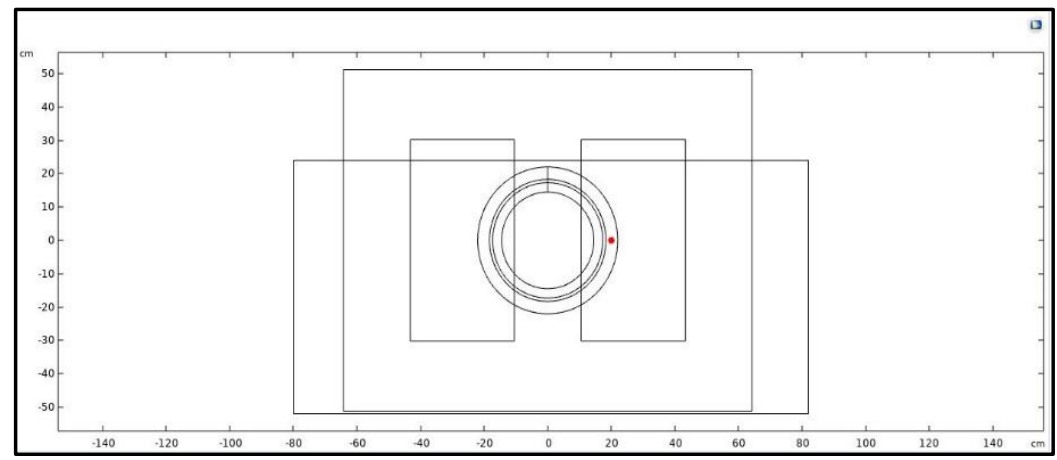

Figure 2: Hotspot evaluation point

\subsection{Determination of hotspot temperature in IEEE standard}

According to the C57.110-2008 IEEE standard [16], the sequential steps to calculate the hotspot temperature for oil-type transformer can be obtained by taking the consideration of the harmonic load factor. Most of manufacturing industry players were using this standard guideline in order to design their electrical equipment such as the transformer. Below are the summarized steps to determine the hotspot temperature on the winding of the transformer.

First of all, the transformer losses are generally the summation of no load losses and load losses as shown in the equation (3) below:

Where,

$$
P_{T}=P_{N L}+P_{L L} \ldots
$$

$$
\begin{aligned}
& P_{T}=\text { total loss in watt }(\mathrm{W}) \\
& P_{N L}=\text { no load loss in watt }(\mathrm{W}) \\
& P_{L L}=\text { load loss in watt }(\mathrm{W})
\end{aligned}
$$

The no load loss which normally provided by the manufacturer are the losses from the voltage excitation of the core. Meanwhile, the load loss can be divided into $\mathrm{I}^{2} \mathrm{R}$ loss and stray loss which caused by electromagnetic 
flux in the winding and other part of the transformer. The stray loss is then can be divided into winding eddy loss, $P_{E C}$ and stray loss, $P_{O S L}$ in components other than the windings. The total load loss can be stated as in equation (4) below:

Where,

$$
P_{L L}=P_{I^{2} R}+P_{E C}+P_{O S L} \cdots
$$

$$
\begin{aligned}
& P_{L L}=\text { load loss in watt }(\mathrm{W}) \\
& P_{I^{2} R}=\text { ohmic loss in watt }(\mathrm{W}) \\
& P_{E C}=\text { eddy current loss in watt }(\mathrm{W}) \\
& P_{O S L}=\text { other stray loss in watt }(\mathrm{W})
\end{aligned}
$$

Next in this section is the harmonic loss factor, FHL which is the main factor of the current harmonic impact on the winding eddy loss and other stray loss. These FHL were actually the ratio of the total losses due to the harmonics to the losses at the power frequency. The notation of the FHL for eddy current and other stray loss can be written as $F H L_{e c}$ and $F H L_{o s l}$ respectively. Both eddy current loss and other stray loss were increased by these harmonic load factor as depicted in the equations (6) and (7). Thus, the updated transformer load losses in non-sinusoidal condition can be shown in equation (5) below:

$$
\begin{aligned}
& P_{L L}=P_{I^{2} R}+F H L_{e c} P_{E C}+F H L_{o s l} P_{O S L} \cdots \\
& F H L_{e c}=\frac{\sum_{h=1}^{h=\max }\left[\frac{I_{h}}{I_{1}}\right]^{2} h^{2}}{\sum_{h=1}^{h=\max }\left[\frac{I_{h}}{I_{1}}\right]^{2}} \ldots \\
& F H L_{o s l}=\frac{\sum_{h=1}^{h=\max }\left[\frac{I_{h}}{I_{1}}\right]^{2} h^{0.8}}{\sum_{h=1}^{h=\max }\left[\frac{I_{h}}{I_{1}}\right]^{2}} \ldots
\end{aligned}
$$

Where,

$$
\begin{aligned}
& h=\text { harmonic order } \\
& F H L_{e c}=\text { harmonic factor for eddy current loss } \\
& F H L_{o s l}=\text { harmonic factor for other stray loss }
\end{aligned}
$$

Finally, the formula to get the total hot spot temperature, $\left(\Theta_{H}\right)$ is by the summation of three division of the temperature which is the ambient temperature $\left(\Theta_{A}\right)$, winding rise temperature $\left(\Theta_{g}\right)$ and top oil rise temperature $\left(\Theta_{T O}\right)$ as in the following equation (8), (9) and (10):

$$
\begin{gathered}
\Theta_{T O}=\Theta_{\text {TO-rated }}\left(\frac{P_{L L-C}+P_{N L}}{P_{L L-\text { rated }}+P_{N L}}\right)^{0.8} \ldots \\
\Theta_{g}=\left(\Theta_{w}-\Theta_{\text {TO-rated }}\right)\left(1+\frac{F H L_{e c}\left(P_{\text {ec-rated } p u}\right)}{1+P_{\text {ec-rated } p u}} \times P_{L L-p u}\right)^{0.8} \ldots \\
\Theta_{H}=\Theta_{A}+\Theta_{T O}+\Theta_{g} \ldots(10)
\end{gathered}
$$

Where,

$P_{L L-C}=$ corrected power loss in watt $(\mathrm{W})$

$\Theta_{T O}=$ oil temperature rise in degree celcius $\left({ }^{\circ} \mathrm{C}\right)$

$\Theta_{w}=$ winding temperature rise in degree celcius $\left({ }^{\circ} \mathrm{C}\right)$

$\Theta_{A}=$ ambient temperature in degree celcius $\left({ }^{\circ} \mathrm{C}\right)$

$\Theta_{g}=$ hottest spot conductor rise over top oil temperature in degree celcius $\left({ }^{\circ} \mathrm{C}\right)$

$\Theta_{H} \quad=$ total hot spot temperature in degree celcius $\left({ }^{\circ} \mathrm{C}\right)$ 


\section{RESULTS AND DISCUSSION}

As been mentioned in the previous section, the model to illustrate the three phase transformer had been simplified to avoid complexity in calculation. In the final, the mesh of the model can be seen in the figure below. In the modeling, the mesh was selected for the finer mesh as to get the most optimum result in the simulation.

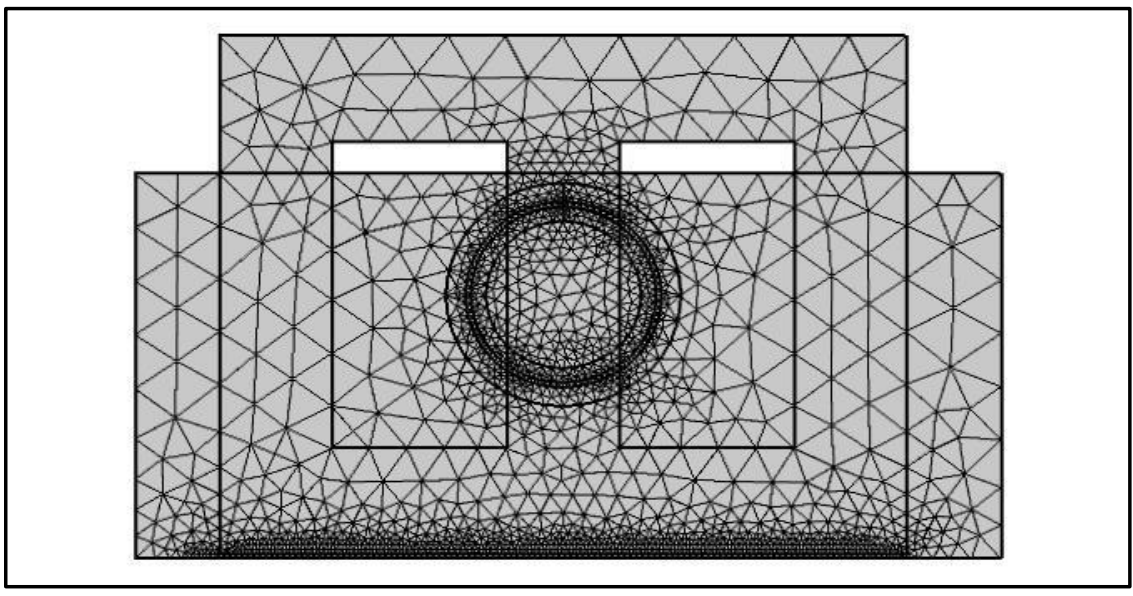

Figure 3. The discretised mesh of the transformer thermal model

\subsection{Hot spot temperature under rated load (without harmonic)}

In order to significantly observe the effect of harmonic content towards the hotspot temperature on the transformer winding, the thermal transformer model was initially being simulated with rated load at $50 \mathrm{~Hz}$ frequency system. The temperature graph in figure 4 has shown the simulation result of the selected point that had mentioned earlier and the hottest spot temperature was discovered to be at $63.89^{\circ} \mathrm{C}$ for entire three phase of the transformer winding. Noted here that the hottest spot temperature under rated load has not exceeds the limit of the rated $65^{\circ} \mathrm{C}$ hottest spot rise. Hence to be said that the transformer is operated under an ideal state and its design lifetime expentancy is secured.

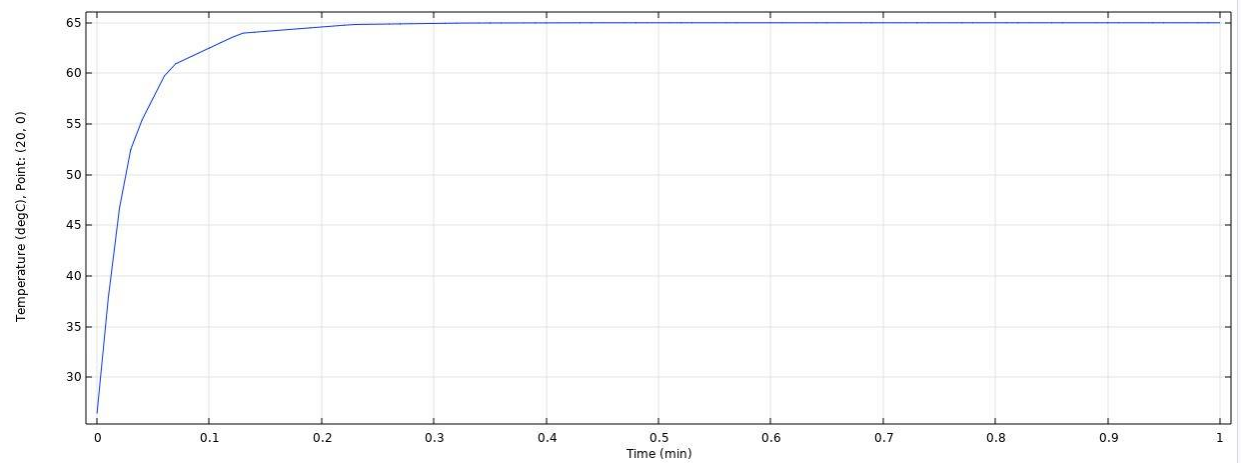

Figure 4. The hotspot temperature graph after completion of transient study with rated load.

\subsection{Hot spot temperature under non-linear load (with harmonic)}

The thermal transformer model were then tested with the nonlinear loads that conceived of harmonic current content along the phases. The analysis were done for unbalanced harmonic loads where each of phases had generated self power losses due to the eddy current which is the winding and other stray part of the model. Below figures 5-7 had illustrated the contribution of the harmonic current towards the total winding losses. Figure 5 had shown the hotspot temperature at Phase A of the transformer. The maximum hottest spot temperature of selected evaluation point was at $81.96^{\circ} \mathrm{C}$ and it has exceeded the $65^{\circ} \mathrm{C}$ reference hottest spot temperature. 


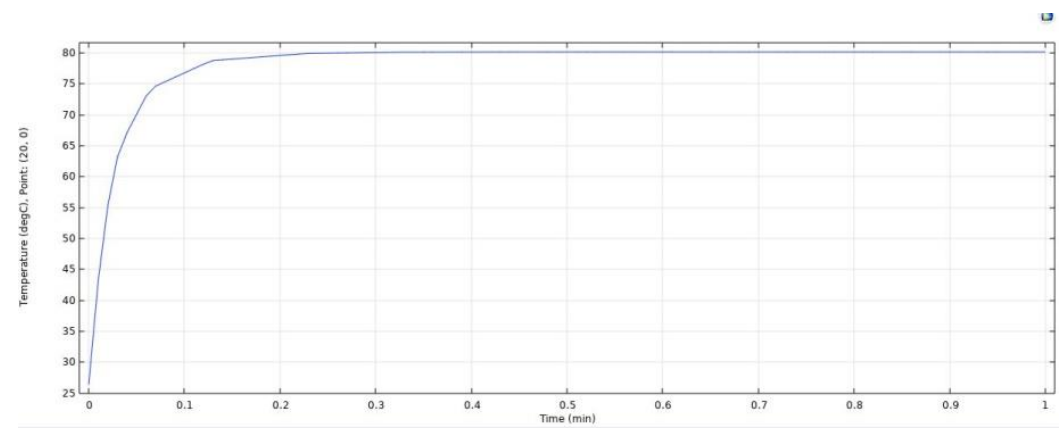

Figure 5. The temperature distribution after completion of transient study with phase A loading.

The next simulation was for the total loss at Phase B as illustrated in Figure 6. The maximum hottest spot temperature of this model had achieved was at $85.12^{\circ} \mathrm{C}$ which also has exceeded the $65^{\circ} \mathrm{C}$ reference hottest spot temperature. The hottest spot temperature in this phase was slightly higher than the phase A where about 3.16 difference in value.

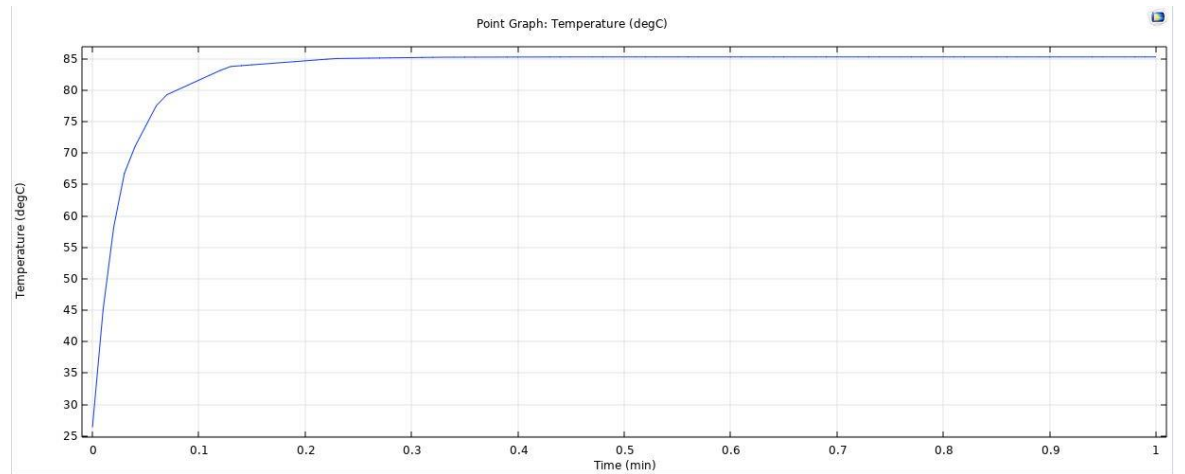

Figure 6. The temperature distribution after completion of transient study with phase B loading.

The final simulation on the thermal transformer model was for the total loss from the Phase $\mathrm{C}$ as in Figure 7. It has discovered the hottest spot temperature of this model was at $82.08^{\circ} \mathrm{C}$ which also exceeded the $65^{\circ} \mathrm{C}$ reference hottest spot temperature. The hottest spot value from this phase was to be at the middle when compared to the other two phases.

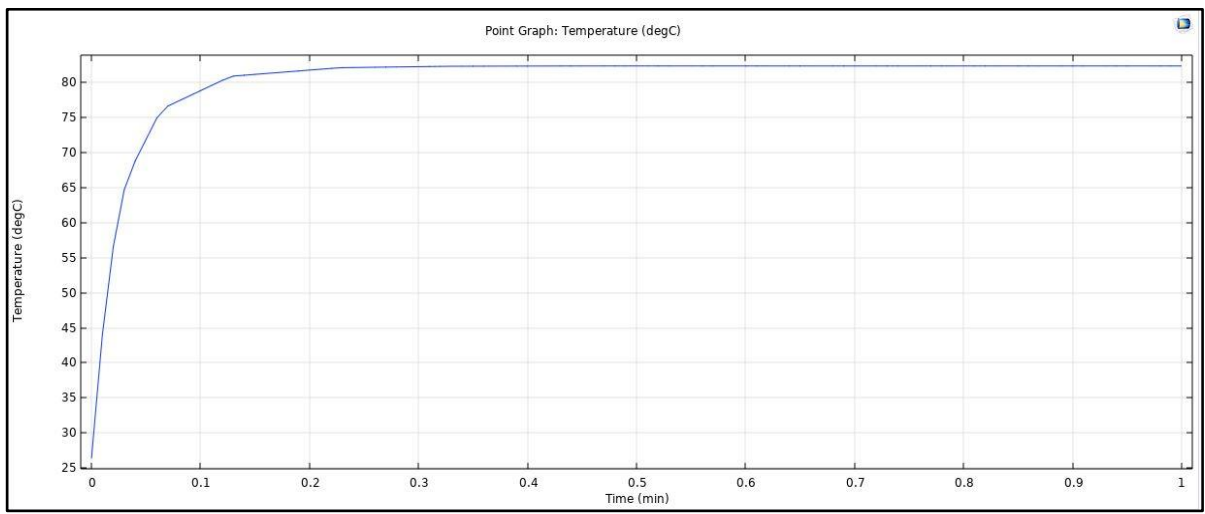

Figure 7. The temperature distribution after completion of transient study with phase $\mathrm{C}$ loading.

In summary, based on the simulation results from total phases, it has depicted the vivid visual of the temperature rise increment in all phases. This also means that harmonic load currents has shaken the quality of the oil transformer and also the transformer itself. The increment up to about $80^{\circ} \mathrm{C}$ in every phase has caused the transformer to be at the warning level. Other that than, the difference value of the temperature rise of each phases has clearly shown the significant of this study which is to analyse the thermal model under unbalanced harmonic loads condition. In any actual distribution network system, the normal loads will never be similar in 
each of the phases. Hence, by only consider the balanced condition in any study or investigation for any critical system like transformer is said to be not accurate or not good enough.

\subsection{Validation of hotspot temperature modeling in FEM modeling with IEEE Standard}

As for this paper, the hotspot temperature results from the FEM modeling in COMSOL were validated with the International IEEE standard as depicted in the Table 5 below [2]. Based on the agreement from the standard, it clearly had shown that FEM method be able to generate precise result from its modeling and can terminate all the tedious manual calculations and lab tests in order to see the hotspot temperature from transformer. In addition, it also can solve the technical problem due to the broken sensors which is expected to give an indication of the transformer temperature condition level.

Table 5. Comparison hotspot temperature between FEM modelling and IEEE standard

\begin{tabular}{ccc}
\hline Rated Load & $65.0^{\circ} \mathrm{C}$ & $64.3^{\circ} \mathrm{C}$ \\
Load at Phase A & $82.2^{\circ} \mathrm{C}$ & $81.6^{\circ} \mathrm{C}$ \\
Load at Phase B & $85.3^{\circ} \mathrm{C}$ & $84.7^{\circ} \mathrm{C}$ \\
Load at Phase C & $83.5^{\circ} \mathrm{C}$ & $82.1^{\circ} \mathrm{C}$ \\
\hline
\end{tabular}

\subsection{Comparison hot spot temperature with and without harmonic.}

Figure 8 below had depicted the significant comparison between the hottest spot temperature under rated load (ideally without any harmonic content) and under nonlinear unbalanced load condition (with odd order harmonic current content). There was about $28.28 \%, 33.23 \%$ and $28.47 \%$ in hotspot temperature increment in Phase A, Phase B and Phase $\mathrm{C}$ respectively compared to the hottest spot temperature under rated load. By average, the total increment of hottest spot temperature was to be at $29.99 \% \approx 30 \%$ from the rated loads (without harmonic) toward the nonlinear loads (with harmonic).

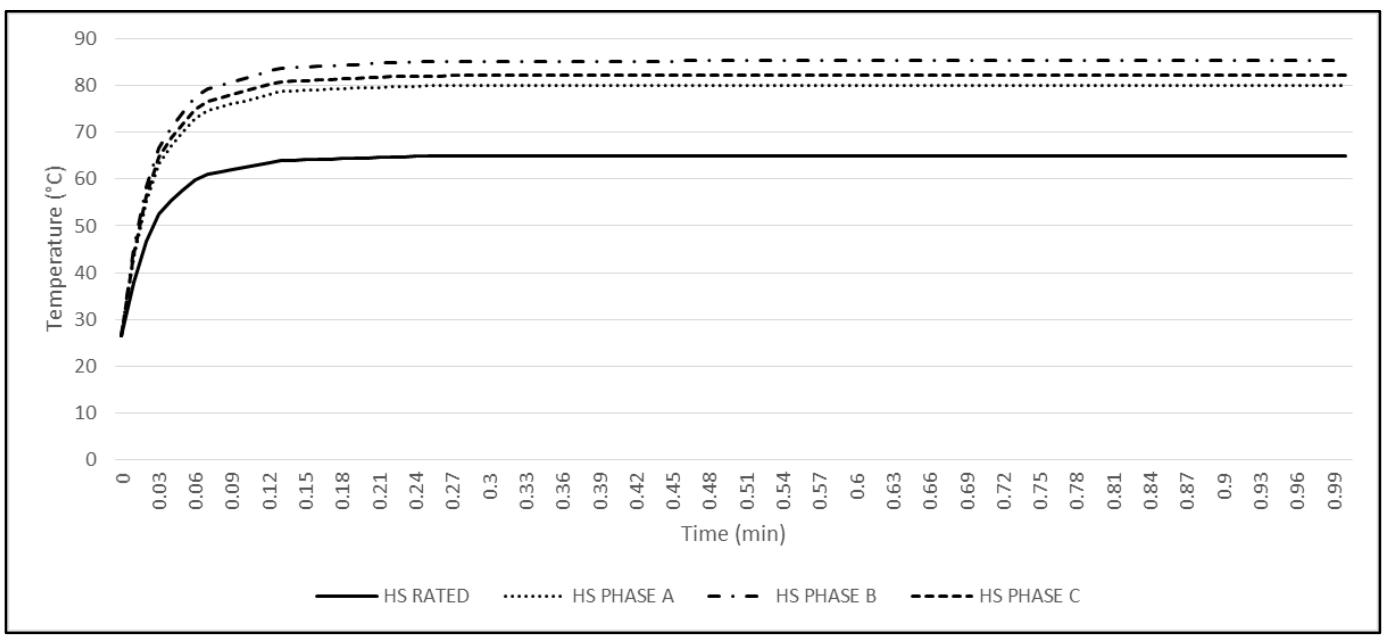

Figure 8. Hotspot temperature at rated load (without harmonic) and unbalanced nonlinear load (with harmonic)

\section{CONCLUSION}

As a conclusion, from the modeling result, it is proven that the winding loss that act as a heat source to the model has rise up the initial temperature in the transformer. Based on the simulation result, it has prove the significant of the study which is to analyse the temperature rise under unbalanced harmonic loads in order to obtain precise analysis. Hence by this precise analysis, it can be a best reference for research study in order to detect the premature failure of the transformer due to the additional heating that has increase the temperature on the transformer. Not limited in reserving the laborious maintenance works and cost, the detection of premature failure hence can avoid a massive loss that could be happen from the fatal transformer failure or breakdown. 


\section{ACKNOWLEDGMENTS}

The authors would like to express the appreciation to the Ministry of Education Malaysia (MOE), the support of the sponsors [Vot Number = Q.J130000.2423.03G88 and R.J130000.7351.4J347] and also to the Universiti Teknologi Malaysia (UTM) for providing the best education and research facilities in order for to achieve the aims and goals in research studies and works.

\section{REFERENCES}

[1] 519-2014 - IEEE Recommended Practice and Requirements for Harmonic Control in Electric Power Systems IEEE Std.

[2] Jaspreet Singh, et al., "Effect of Harmonics on Distribution Transformer Losses and Capacity," 2017 International Journal of Engineering Technology Science and Research IJETSR, vol. 4, no. 6, June 2017.

[3] William H. Bartley, HSB, "Analysis of Transformer Failures," Proceedings of the Thirty Six Annual Conference, Stockholm, 2003.

[4] T. Dao and B. T. Phung, "Study of voltage harmonic effect on temperature rise in distribution transformer, " presented at the 2016 IEEE International Conference on Power System Technology (POWERCON), Wollongong, Sydney, 2016.

[5] Thinh Dao and B.T. Phung, "A Study of Hot-Spot Localization in Distribution Transformers," 1st International Conference on Electrical Materials and Power Equipment - Xi'an - China, 2017.

[6] Abbas, Ahmed, E. Abou Elzahab, and Ahmed Elbendary. "Thermal modeling and ageing of transformer under harmonic currents." 23rd International Conerence. Electricity Distribution. 2015.

[7] Cazacu, Emil, Valentin Ionita, and Lucian Petrescu. "Thermal aging of power distribution transformers operating under nonlinear and balanced load conditions." 2018.

[8] D. J. Kweon, K. S. Koo, J. W. Woo, and J. S. Kwak, "A Study on the Hot Spot Temperature in 154kV Power Transformers" Journal of Electrical Engineering and Technology, vol. 7, pp. 312-319, 2012.

[9] G. Betta, A. Pietrosanto, and A. Scaglione, "An Enhanced Fiber-Optic Temperature Sensor System for Power Transformer Monitoring," IEEE Transactions on Instrumentation and Measurement, vol. 50, pp. 11381143, 2002.

[10] Haque, Nasirul \& Ittiarah, Jijo \& Gangopadhyay, Tarun \& Chakravorti, Sivaji. "Temperature monitoring of power transformer using fiber-optic sensor."2015 1st Conference on Power, Dielectric and Energy Management at NERIST, ICPDEN 2015. 10.1109/ICPDEN, 2015.

[11] Jalilian, Maisam, et al. "Design and implementation of the monitoring and control systems for distribution transformer by using GSM network." International Journal of Electrical Power \& Energy Systems 74, 2016.

[12] Vani, Laknapuram Sai. "Distribution and Load Sharing of Transformer Automatically by Using Microcontroller." International Research Journal of Engineering and Technology (IRJET) 4.05, 2017.

[13] Azmi, M. A. M., et al. "Transformer Fault Early Warning System Model Using GSM Network." Proceeding of the Electrical Engineering Computer Science and Informatics 2.1, 2015.

[14] IEC, "Power Transformmers - Part 2: Temperature rise for liquid immersed transformers," ed: IEC, 2011.

[15] K. M. Takami, H. Gholnejad, and J. Mahmoudi, "Thermal and hot spot evaluations on oil immersed power Transformers by FEMLAB and MATLAB software's," presented at the International Conference on Thermal, Mechanical and Multi-Physics Simulation Experiments in Microelectronics and Micro-Systems, 2007. EuroSime 2007, London, 2007.

[16] C57.110-2008 "IEEE Recommended Practice for Establishing Transformer Capability When Supplying Nonsinusoidal Load Currents".

[17] Santisteban, A., et al. "Numerical analysis of the hot-spot temperature of a power transformer with alternative dielectric liquids." IEEE Transactions on Dielectrics and Electrical Insulation 24.5 (2017): 3226-3235.

[18] J.C.Das, Power System Analysis, Short-circuit load flow and Harmonics, $2^{\text {nd }}$ ed., New Jersey, NJ: Wiley, 2012.

[19] J. Wijaya, T. Czaszejko, N. Lelekakis, D. Martin, and D. Susa, "A Finite Element Model for the Analysis of Steady State Heat Transfer in Disc Coil Transformer Winding," presented at the 22nd Australasian Universities Power Engineering Conference (AUPEC) 2012, 2012.

[20] Azizi, Diako, Ahmad Gholami, and Diar Azizi. "Hot spot temperature analysis in 3 phase transformers using FEM method." International Journal of Modern Engineering Research (IJMER), 2011.

[21] Yadav, J. Mahesh, and A. Srinivasula Reddy. "Prediction of Hotspot Location in a Power Transformer Considering Stray Losses using FEM." International Journal of Applied Engineering Research 13.1, 2018.

[22] Yusoff, Nor Azizah Mohd, et al. "Multiphase transformer modelling using finite element method." International Journal of Power Electronics and Drive Systems 6.1, 2015.

[23] Teke, I., Özüpak, Y., \& Mamiş, M.. "Electromagnetic Field and Total Loss Analysis of Transformers by Finite Element Method." International Journal of Engineering and Computer Science, 8(01), 24451-24460, 2019.

[24] Haitha, V. S. "Thermal Modeling of Electrical Transformers." Proceedings. 2010.

[25] Behjat, Vahid. "A coupled thermal-electromagnetic FEM model to characterize the thermal behavior of power transformers damaged by short circuit faults." International Journal of Electrical Energy 1.4, 2013.

\section{BIOGRAPHY OF AUTHORS}

Impact of unbalanced harmonic loads towards winding temperature rise ... (Z.I.M.Yassin et al) 

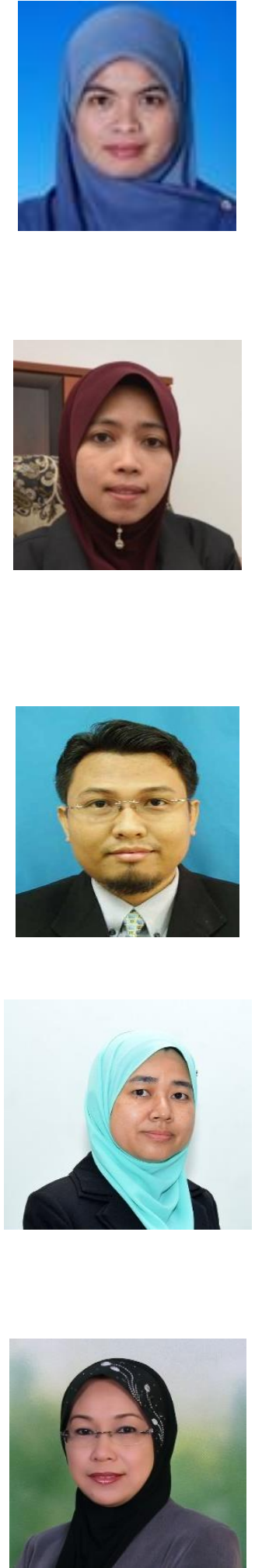

Ms. Zaris Izzati is a final PhD student at Centre of Electrical Energy Systems, School of Electrical Engineering, Faculty of Engineering, Universiti Teknologi Malaysia (UTM). She obtained her B.Eng in Electrical Engineering 2012 and M.Eng in Electrical Engineering in 2014 from Universiti Tun Hussein Onn Malaysia (UTHM). She has started her $\mathrm{PhD}$ research since 2015 until recently. She has an experience with finite element method as her degree final year project was to investigate the distribution field of magnetostatic using the method. Meanwhile, for her master final year project, she was exposed and exprienced the deregulated electricity market environment for Malaysia. Her area for her current PhD research is on Power Quality of Electrical Network System and focusing on the power quality disturbance on the electrical transformer.

Dr. Dalila Mat Said is a Senior Lecturer at Centre of Electrical Energy Systems, School of Electrical Engineering, Faculty of Engineering, Universiti Teknologi Malaysia (UTM). She obtained her B.Eng. in Electrical Engineering in 2000, M.Eng in Electrical Engineering in 2003 and $\mathrm{PhD}$ in Power Quality in 2012 from Universiti Teknologi Malaysia. She has 10 years of experience in teaching electrical engineering courses and supervision of more than 20 undergraduates, and 10 post graduate's students. She has an experience within the area of power quality consultancy. She was involved in the Power Quality Baseline Study in a Peninsular Malaysia (2010-2013) under the Energy Commission of Malaysia. She is a member of Institute Electrical Electronic Engineer (MIEEE), Registered Graduate Engineer with the Board of Engineers Malaysia (BEM) and a Graduate Member of Institution of Engineers Malaysia (IEM). Her research interests are power quality and power system measurement and monitoring.

Mr.Nasarudin Ahmad is a lecturer at Control and Instrumentation Engineering Department (CIED), School of Electrical Engineering, Universiti Teknologi Malaysia since year 2000. He received B. Sc and M. Sc degrees in electrical engineering from Universiti Teknologi Malaysia, in 1998 and 2000 respectively. His interest for research activities are application of instrumentation technique in power system.

Dr. Nik Noordini Bt Nik Abd Malik is a Senior Lecturer at School of Electrical Engineering, Faculty of Engineering, University Teknologi Malaysia (UTM). She obtained her B.Eng in Electrical Engineering (Telecommunication) from University Teknologi Malaysia in 2003 and her M.Eng in Radio Frequency (RF) and Microwave Communication Engineering from University of Queensland (UQ), Australia in 2005. She obtained her Doctor of Philosophy (PhD) in Electrical Engineering from Universiti Teknologi Malaysia in 2015 with her research entitled Collaborative Beamforming for Wireless Sensor Network (WSN) using Particle Swarm Analysis. Her research interests were on Collaborative Beamforming, Wireless Sensor Networks (WSNs), Bio-inspired optimization algorithms and Array Antennas.

Ir. Hayati Abdullah is an Associate Professor at the School of Mechanical Engineering, Faculty of Engineering Universiti Teknologi Malaysia (UTM) and currently holds the position as Director of the Centre for Teaching and Learning at the UTM Academic Leadership, UTMLead. Ir. Hayati specialises in Thermodynamics, more particularly in the area of Air-Conditioning and Energy Management. She was trained in Energy Management in Sweden and is a Certified Energy Manager. She is also a Registered Electrical Energy Manager with the Energy Commission Malaysia. Her working experiences include serving as consultants for numerous local energy intensive industries as well as collaboration with international energy management consultants from Japan and ADEME, France. Ir. Hayati is a Professional Engineer with Practising Certificate registered with the Board of Engineers, Malaysia and a Chartered Engineer registered with The Engineering Council, United Kingdom. 